\title{
Cold Storage of Selected Members of the Proteaceae and Australian Native Cut Flowers
}

\author{
Rod Jones and John Faragher \\ Institute of Plant Sciences, Knoxfield, Department of Agriculture, \\ Victoria, PO Box 174, Ferntree Gully 3156 Australia
}

Additional index words. Leucospermum spp., Protea spp., Leucadendron, Thryptomene calycina , Telopea speciosissima , Chamelaucium uncinatum, Vertcordia spp .,

Anigozanthos spp., postharvest physiology, vase life

\begin{abstract}
Five members of the Proteaceae and 13 Australian native cut flower cultivars were stored for 35 days under standard conditions at $1 \mathrm{C}$ to assess their ability to withstand long-term storage and transport. Protea cynaroides L., Leucadendron 'Silvan Red', Leucospermum 'Firewheel', Thryptomene calycina (Lindl.) Stapf., Telopea speciosissima R. Br., and Verticordia grandtiflora Endl. retained a vase life of at least 7 days after 21 days of storage. Leucospermum cordifolium Salisb. ex Knight, Protea neriifoli R. Br., Chamelaucium uncinatum 'Alba', C. uncinatum 'Purple Pride', Verticordia monadelpha Turcz., Verticordia plumosa (Desf.) Druce, and Verticordia nitens (Lindl.) Schau. suffered a decline in vase life ranging from $31 \%$ to $100 \%$ after 14 to 21 days of storage. Species of Verticordia and Chamelaucium were particularly susceptible to fungal infection. Anigozanthos pulcherrimus Hook. and the Anigozanthos cultivars Ruby Delight, Bush Harmony, Bush Haze, and Gold Fever all showed a significant reduction in vase life after 14 days of storage compared with unstored controls.
\end{abstract}

Early research on the postharvest handling of cut flowers demonstrated the potential of dry storage in the rose, carnation, and chrysanthemum (Fischer, 1952; Hauge et al., 1947; Neff, 1939; Thornton, 1930). Recent studies have also concentrated on storage protocols for traditional flower crops (Goszczynska and Rudnicki, 1988; Hardenburg et al., 1986) The rapid expansion of the Australian cut flower industry has resulted in a marked increase in the export trade of Aus-

Received for publication 21 Mar. 1991. This work was partially- funded by a grant from the Rural Industry Research Development Corn. We thank Ausflora Pacific Pty. Ltd.; The Australian Protea Growers Assn., Australian Flower Exporters Ply. Ltd, and Growth Industries Ltd. for supplying the flowers used in this study. We are also greatly indebted to Janyce Truett for her skilled technical assistance and Peter Franz for assistance with statistical analysis. The cost of publishing this paper was defrayed in part by the payment of page charges. Under postal regulations, this paper therefore must be hereby marked advertisement solely to indicate this fact. tralian native cut flowers, particularly $\mathrm{Cha}$ melaucium uncinatum (Geraldton waxflower), Anigozanthos cultivars (kangaroo paw), and members of the Proteaceae. In the few storage trials conducted using these crops, the vase life of Telopea speciosissima (waratah) was reduced by $25 \%$ after 28 days of storage at 1C (Faragher, 1986), while vase life in Anigozanthos rufus and Chamelaucium uncinatum was significantly reduced by 14 days of storage at 1C (Joyce, 1988; Seaton and Joyce, 1989). P. cynaroides and $L$. cordifolium withstood 42 days of dry storage at $2 \mathrm{C}$ without reduction in vase life (Haasbroek et al., 1973; Ireland et al., 1967; Meynhardt, 1976). During a transient period of high airfreight costs, successful seafreight of cut Protea flowers from Cape Town, South Africa, to Rotterdam, Holland, was completed by several South African Protea growers in 1980 using refrigerated containers, but no data exist on storage and transport protocol (J. Wood, personal communication). Storage protocols and conditions differed widely between these trials, and in many cases the criteria for determining the end of vase life were not cited. The aim of this study was to assess the storage capacity of a wide range of commercial Australian native cut flowers and members of the Proteaceae family using specific vase life criteria and under a standard storage protocol. Cultivars that were suited to long-ten dry storage were determined to be those that retained a vase life of at least 7 days after 21 days of storage.

Verticordia spp. were obtained from Western Australia and airfreighted to Knoxfield within $30 \mathrm{~h}$ of harvest. The Chamelaucium and Anigozanthos cultivars were harvested from commercial flower growers, cooled for $6 \mathrm{~h}$, and transported dry for 6 to $12 \mathrm{~h}$ to the laboratory. All other flowers were harvested locally and transported in water, arriving at the laboratory within $3 \mathrm{~h}$ of harvest. Control, unstored flowers were sprayed with $1 \mathrm{~g}$ iprodione/liter (wettable powder, $50 \%$ a.i.; commercial name: Rovral, Rhone Poulenc, Melbourne, Australia) and placed in water at $1 \mathrm{C}$ for $24 \mathrm{~h}$, then removed to $20 \mathrm{C}$ for vase life assessment. Stored blooms were thoroughly sprayed with $1 \mathrm{~g}$ iprodione/liter, allowed to dry, and kept at $1 \mathrm{C}$ for $24 \mathrm{~h}$ while standing in distilled water. Preliminary trials indicated that a pre- and poststorage treatment in water lasting at least $24 \mathrm{~h}$ was most effective (data not shown).

Flowers were bunched and tightly wrapped in two layers of newsprint and placed in lowdensity polyethylene bags ( $38 \mu \mathrm{m}$ thick). These were then placed in fiberboard flower boxes $(1030 \times 370 \times 160 \mathrm{~mm})$ and stored in a room set at $1 \pm 1 \mathrm{C}$ and $80 \% \pm 5 \%$ relative humidity $(\mathrm{RH})$. A nonstored control group was placed directly into the evaluation

Table 1. Criteria used for determining end of vase life.

\begin{tabular}{|c|c|}
\hline Genus & Termination of vase life \\
\hline $\begin{array}{l}\text { Leucosper- } \\
\text { mum }\end{array}$ & First sign of wilting styl \\
\hline Protea & $\begin{array}{l}\text { Wilting styles and/or first sign of } \\
\text { leaf blackening }\end{array}$ \\
\hline on & Desiccation of leaf tips \\
\hline 2 & \\
\hline 16 & $\mathrm{~d} /$ or blue color \\
\hline $\begin{array}{l}\text { Chamelau- } \\
\text { cium }\end{array}$ & $\begin{array}{l}\text { First sign of flower closing and } \\
\text { abscission }\end{array}$ \\
\hline Verticordia & $\begin{array}{l}\text { First sign of flower closing and } \\
\text { abscission and/or fading }\end{array}$ \\
\hline Anigozanthos & Wilting flowers and/or fading \\
\hline
\end{tabular}




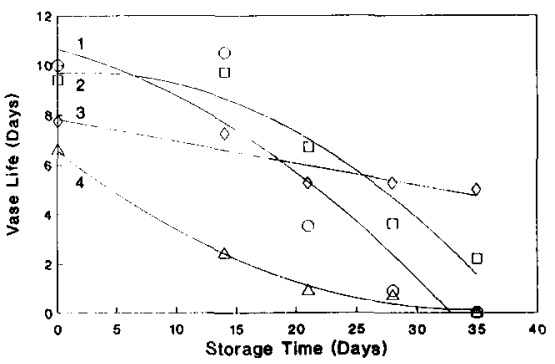

Fig. 1. Fitted curves representing changes in vase life after dry storage at $1 \mathrm{C}$ in members of the Proteaceae. 1) L. cordifolium ( $\bigcirc) ; \mathrm{Y}=$ $10.66-0.129 \mathrm{X}-0.00596 \mathrm{X} ;$ Adj. $R^{2}=$ 60.4. $\mathrm{SE}=0.128 \mathrm{X} ; 0.00353 \mathrm{X}^{2}$. 2) Firewheel ( $\square) ; \mathrm{Y}=9.68+0.033 \mathrm{X}-0.00756 \mathrm{X}^{2}$; Adj. $R^{2}=39.4$. SE $=0.137 \mathrm{X} ; 0.00378 \mathrm{X}^{2}$. 3) $P$. cynaroides $(\diamond) ; \mathrm{Y}=7.83-0.0883 \mathrm{X} ;$ Adj. $R^{2}=17.9$. SE $=0.0389 \mathrm{X}$. 4) $P$. neriifolia $(\Delta) ; Y=6.58-0.374 \mathrm{X}+0.00542 \mathrm{X}^{2} ;$ Adj. $R^{2}=76.4 . \mathrm{SE}=0.0508 \mathrm{X} ; 0.004 \mathrm{X} 2$. Where

$\mathrm{Y}=$ vase life (days); $\mathrm{X}=$ storage time (days).

room. After storage, the flowers were unwrapped, the stems recut and rehydrated at $1 \mathrm{C}$ in distilled water for $24 \mathrm{~h}$, with flower heads covered with a polyethylene bag similar to that used in packing to increase relative humidity in the air surrounding the flower heads. Vase life was evaluated at $20 \mathrm{C}$ and $55 \%$ to $65 \% \mathrm{RH}$ under constant light (10 $\left.\mu \mathrm{mol} \cdot \mathrm{m}^{-2} \cdot \mathrm{s}^{-1}\right)$ supplied by cool-white fluorescent lamps. Criteria used to specify the end of vase life for each species and cultivar were defined (Table 1).

Each treatment (storage time) consisted of 10 replicate stems, and each storage trial was repeated twice. Regression analysis was performed on the data. Those stems infected with fungal growth during storage were arbitrarily assigned a vase life of zero, and these values were included in the calculation of mean vase life.

Proteaceae. Leucadendron 'Silvan Red', Leucospermum 'Firewheel', and Protea cynaroides retained a vase life of at least 7 days after 21 days of storage (Figs. 1 and 2). The vase life of 'Silvan Red' had decreased by only $11 \%$ ( 25 days compared with 28 days in unstored controls) after 28 days of storage

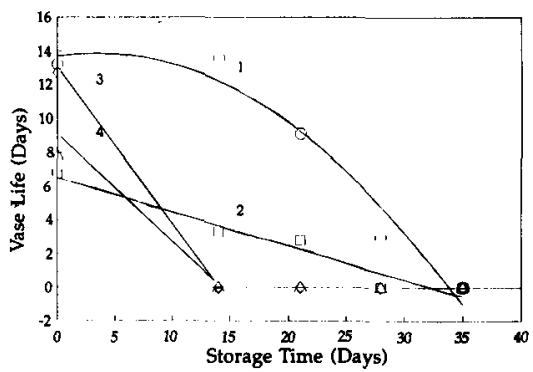

Fig. 4. Fitted curves representing changes in vase life in Verticordia spp. after dry storage at $1 \mathrm{C}$. 1) $\mathrm{V}$ grandiflora $(\mathrm{o}) ; \mathrm{Y}=13.67+0.1049(\mathrm{X})$ $-0.01499\left(\mathrm{X}^{2}\right)$; $\mathrm{Adj} . R^{2}=92.9 . \mathrm{SE}=$ $\left.0.0587(X) ; 0.0016\left(\mathrm{X}^{2}\right) .2\right) V$. nitens $(\square)$; $\mathrm{Y}=6.503-02012(\mathrm{X}) ;$ Adj $R^{2}=72.0$. $\mathrm{SE}$ $=0.0178(\mathrm{X}) .3) \mathrm{V}$ monadelpha $(\diamond) . \mathrm{No}$ regression equation. 4) $V$. pulmosa (A). No regression equation. Where $\mathrm{Y}=$ vase life (days); $\mathrm{X}=$ storage time (days).

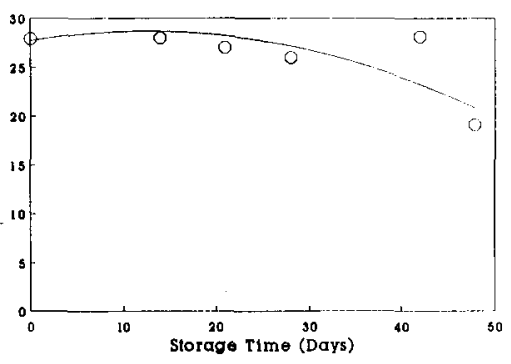

Fig. 2. Fitted curve representing change in vase life in Leucadendron 'Silvan Red' after dry storage at $1 \mathrm{C}$. $\mathrm{Y}=27.72+0.156 \mathrm{X}-$ $0.00626 \mathrm{X}^{2}$, Adj. $R^{2}=25.2 . \mathrm{SE}=0.182 \mathrm{X}^{2}$, $0.00321 \mathrm{X}^{2}$. Where $\mathrm{Y}=$ vase life (days); $\mathrm{X}=$ storage time (days).

(Fig. 2), and storage was therefore continued for an additional 21 days. 'Silvan Red' maintained a commercially acceptable vase life of 19 days even after 49 days of storage (Fig. 2).

Poststorage vase life of Leucospermum cordifolium declined rapidly after 14 days of storage, mainly due to fungal infection (data not shown). A more effective anti-fungal treatment than we used probably would dramatically improve poststorage vase life in this flower. Preliminary trials with L. cordiforium indicated that stems not infected with fungal rot during storage had a vase life of at least 7 days after 21 days of storage.

Cold storage-induced leaf blackening after 14 days of storage in $P$. neriifolia resulted in a short poststorage vase life. Storage-induced leaf blackening was not observed in $P$. cynaroides.

Australian native cut flowers. Generally, Australian native cut flower species stored in these trials did not withstand the rigors of dry storage as well as members of the Proteaceae family (Figs. 3,4, and 5). However, vase life in Thryptomene calycina and Telopea speciosissima did not change significantly after 21 days of storage (11 and 7

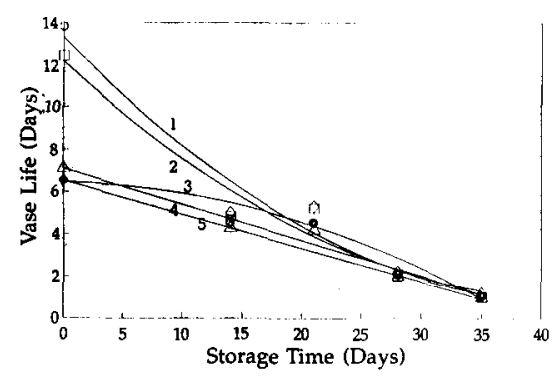

Fig. 5. Fitted curves representing vase life in kangaroo paw cultivars after dry storage at $1 \mathrm{C}$. 1) 'Gold Fever' ( $\bigcirc$ ); $\mathrm{Y}=13.3-0.578 \mathrm{X}+$ $0.00659 \mathrm{X}^{2}$. Adj. $R^{2}=83.5 . \mathrm{SE}=0.0757 \mathrm{X}$; $0.00208 \mathrm{X}^{2}$. 2)A. pulcherrimus ( $\left.\square\right) ; Y=12.17$ $-0.521 \mathrm{X}+0.0059 \mathrm{X}^{2}$. Adj. $R^{2}=72.0 . \mathrm{SE}$ $\left.=0.0941 \mathrm{X} ; 0.0826 \mathrm{X}^{2} .3\right)$ 'Bush Harmony (0); $\mathrm{Y}=6.45-0.01 \mathrm{X}-0.0042 \mathrm{X}^{2}$. Adj. $R^{2}=$ 69.5. $\mathrm{SE}=0.0498 \mathrm{X} ; 0.00138 \times 2.4)$ 'Bush Haze' $(\Delta) ; \mathrm{Y}=7.1-0.1726 \mathrm{X} ;$ Adj. $R^{2}=80.8$ $\mathrm{SE}=0.012 \mathrm{X} .5$ ) 'Ruby Delight ' $) ; \mathrm{Y}=6.53$ - 0.162X; Adj. $R^{2}=73.6$. SE $=0.014 \mathrm{X}$. Where $\mathrm{Y}=$ vase life (days); $\mathrm{X}=$ storage time (days).

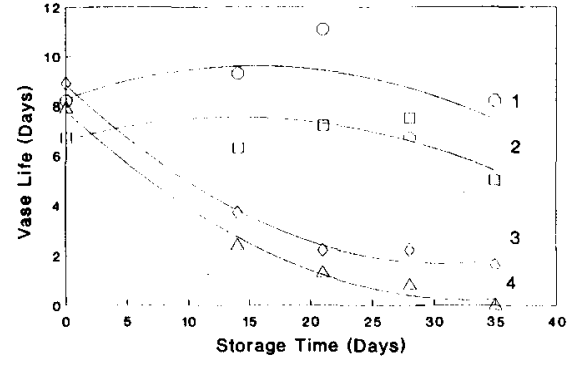

Fig. 3. Fitted curves representing changes in vase life in selected Australian native cut flowers after dry storage at 1C. 1) $T$. speciosissima ( $\bigcirc$ ); $\mathrm{Y}=8.273+0.1744 \mathrm{X}-0.00566 \mathrm{X}^{2}$. Adj. $\left.R^{2}=8.3 . \mathrm{SE}=0.0847 \mathrm{X} ; 0.00234 \mathrm{X}^{2} .2\right) \mathrm{T}$. calycina $(\square) ; Y=6.622+0.1341 X-$ $0.00482 \mathrm{X}^{2}$. Adj. $R^{2}=19.0 . \mathrm{SE}=0.0552 \mathrm{X}$; $0.00153 \mathrm{X}$. 3) C. uncinatum 'Alba' $(\diamond)$; $\mathrm{Y}=$ $8.847-0.4657 \mathrm{X}+0.00756 \times 2$. Adj. $R^{2}=$ 81.7. $\mathrm{SE}=0.0489 X ; 0.00135 \mathrm{X}^{2}$. 4) C. uncinatum 'Purple Pride' $(\Delta) ; \mathrm{Y}=7.8-0.4582 \mathrm{X}$ $+0.0069 \mathrm{X}^{2}$. Adj. $R^{2}=83.8 . \mathrm{SE}=0.0478 \mathrm{X}$, $0.00132 \mathrm{X}^{2}$. Where $\mathrm{Y}=$ vase life (days); $\mathrm{X}=$ storage time (days).

days, respectively; Fig. ,3).

Verticordia grandiflora maintained a vase life of 10 days after 21 days of storage (Fig. 4), after which vase life declined severely, whereas the vase life of all other species of Verticordia declined significantly after 14 days of storage. No regression analysis was performed on $V$. monadelpha and $V$. plumosa as no stems survived after 14 days of storage.

Significant floral abscission occurred in $\mathrm{T}$. calycina after 28 days of storage $(\approx 15 \%$ to $20 \%$ of flowers). As there was no further abscission during vase life assessment, these stems were rated in a similar manner as control stems. Observations during preliminary trials indicated that abscission became a major problem during storage only when flowers are harvested late in the season and in full flower.

The vase life of stored $T$. speciosissima was 8 days after 35 days of storage, similar to the vase life of unstored control stems (Fig. 3). Faragher (1986) reported that waratah vase life was reduced by $50 \%$ (from 6 to 3 days) if stems were stored at $4 \mathrm{C}$, or if flowers were stored unwrapped, indicating the importance of low temperature (1C) and the need to maintain flower hydration during storage with adequate wrapping.

Quality in both C. uncinatum 'Alba' and 'Purple Pride' declined rapidly after 14 days of storage (Fig. 3). Stems of C. uncinatum were stored with a similar reduction in vase life by Seaton and Joyce (1989). C. uncinatum suffered from fungal attack (identified as Botrytis cinerea Pers.) in these trials, despite a prestorage spray with $1 \mathrm{~g}$ iprodione/ liter, resulting in poor poststorage vase life. Fungal infection was also prevalent in all Verticordia spp. and kangaroo paw cultivars after 21 days of storage. When present, it effectively ended vase life immediately after storage. The Veticordia spp. were not treated with an antifungal agent before air transport from Western Australia to Victoria, and conditions during transit (high temperature, high 
relative humidity) possibly were conducive to fungal attack. Subsequent spraying with $1 \mathrm{~g}$ iprodione/liter was not sufficient to prevent further fungal infection.

The evaluation of other anti-fungal agents and spraying/dipping techniques has established the anti-fungal potential of a mixture of $1 \mathrm{~g}$ iprodione/liter and $1 \mathrm{~g}$ mancozeb/liter (wettable powder, $80 \%$ a.i.; commercial name: Mancozeb, suggested by D. Joyce; data not shown). An effective anti-fungal treatment that can be applied immediately after harvest to improve the storage performance of $C$. uncinatum and Verticordia spp. possibly will be developed.

Kangaroo paw cultivars with a long control vase life (Anigozanthos pulcherrimus and the cultivar Bush Fever) suffered a substantial reduction in vase life after 14 days of storage (Fig. 5), leaving all kangaroo paw cultivars with a vase life of $<7$ days after 14 days of storage. Seaton and Joyce (1989) reported a dramatic decrease in vase life when Anigozanthos rufus cut flowers were stored for 2 weeks at $0 \mathrm{C}$. Vase life significantly increased in unstored kangaroo paws pulsed with sucrose solutions of up to 30\% (Carter et al., 1989; Manning et al., 1989), and it is possible that pre- and poststorage treatment with a sucrose solution might extend vase life significantly.

The vase lives cited in this study represent a minimum value. Further improvements of this storage protocol, including more advanced packaging techniques and the use of solutions containing a germicide and sucrose in the precooling and rehydration phases, should improve the length of storage possible and the condition of flowers after storage.

Our results suggest that Leucospermum 'Firewheel', Protea cynaroides, Leucadendron 'Silvan Red', Thryptomene calycina, Telopea speciosissima, and Verticordia grandiflora can be stored for at least 21 days and retain a commercially acceptable vase life of at least 7 days. Vase life of stored Leucospermum cordifolium, Chamelaucium uncinatum 'Alba' and 'Purple Pride', Verticordia monadelpha, Verticordia plumosa, Verticordia nitens, Anigozanthos pulcherrimus, and the Anigozanthos cultivars Ruby Delight, Bush Harmony, Bush Haze, and Gold Fever declined significantly compared with unstored controls. Australian native species were susceptible to fungal attack during storage. Effective anti-fungal treatments may extend the storage period and vase life of these species.

\section{Literature Cited}

Carter, E.M., D.C. Joyce, and T.J. Enright. 1989. Pulsing native Australian cut flowers with sugar. Proc. Conf. Production and Mktg. Austral. Flora, 13-14 July 1989, Univ. of Western Australia, Perth.

Faragher, J.D. 1986. Effects of cold storage methods on vase life and physiology of cut waratah inflorescences (Telopea speciosissima, Proteaceae). Scientia Hort. 29:163-171.

Fischer, C. 1952. Long-term holding of cut flowers. Proc. Amer. Soc. Hort. Sci. 61:585-592.
Goszczynska, D.M. and R.M. Rudnicki. 1988. Storage of cut flowers. Hort. Rev. 10:35-64.

Haasbroek, F.J., G.G. Rousseau, and J.F. de Villiers 1973. Effect of gamma-rays on cut blooms of Protea compacta R. Br., Protea longiflora Lamarck and Leucospermum cordfolium Salisb. ex Knight. Agroplantae 5:33-42.

Hardenburg, R.E., A.E. Watada, and C.Y. Wang. 1986. The commercial storage of fruits, vegetabls, and florist and nursery stocks. U.S. Dept. Agr., Agr. Hdbk. 66.

Hauge, A., W. Bryant, and A. Laurie. 1947. Packaging of cut flowers. Proc. Amer. Soc. Hort. Sci. 49:427-432.

Ireland, J.P., J.T. Meynhardt, and J.M. Strauss. 1967. When Proteas become sailors-treatment before shipping. Farming in South Africa: Dept. Agr. Tech. Serv., Pretoria, S. Africa, Sept. 1967. p. 33-35.

Joyce, D.C. 1988. Postharvest characteristics of
Geraldton Waxflowers. J. Amer. Soc. Hort. Sci. 13:738-742.

Manning, L.E., D.C. Joyce, and B.B. Lamont. 1989. Postharvest handling of kangaroo paws. Proc. Conf. Production and Mktg. Austral. Flora, 13-14 July 1989, Univ. of Western Australia, Perth.

Meynhardt, J.T. 1976. Proteas-picking and handling. Farming in South Africa; Flower, Ornamental Shrubs and Trees Series no. B5/1976 Dept. Agr. Tech. Serv., Pretoria, S. Africa.

Neff, M.S. 1939. Problems in the storage of cut carnations. Plant Physiol. 14:271-284.

Seaton, K.A. and D.C. Joyce. 1989. Cold storage of Geraldton Wax, kangaroo paw and Banksia. Proc. 5th Austral. Agron. Conf.. Sept. 1989. Univ. of Western Australia, Perth. p.532.

Thornton, N.C. 1930. The use of CO, for prolonging the life of cut flowers with special reference to roses. Amer. J. Bot. 17:614-626. 